\title{
Insignificant correlation between post-operative swelling and early functional outcome after ankle fusion
}

\author{
Raden Andri Primadhi, Renaldi Prasetia, Gibran Alpharian, Hermawan Nagar Rasyid \\ Universitas Padjadjaran Medical School / Hasan Sadikin Hospital, Bandung, Indonesia
}

\begin{abstract}
Introduction Swelling is a common complication following a foot and ankle surgery, and is one of the most prevalent complaints that patients present at the clinics. While it affects patients' satisfaction, the relevance between the swelling and clinical outcome remains unclear. Material and Methods This study assessed volume of foot and ankle swelling in 112 patients with history of ankle fusion, the patients' Foot Function Index (FFI) score, and patients' satisfaction. The relationships between swelling volume and early outcomes were analysed with Pearson's correlation coefficient and a scatter plot. Results The mean of swelling volume increase was $120.0 \pm 96.2 \mathrm{ml}$ (range $5 \sim 400 \mathrm{ml}$ ); pre-operative FFI score mean was $73.7 \pm 4.8 \%$ (range $68 \% \sim 81 \%$ ), 3 months post-operative FFI score mean was $32.8 \pm 5.0 \%$ (range $22 \% \sim 56 \%$ ) and satisfaction scale's median was 1 (satisfied). In the correlation analysis, while the meaningful Pearson's correlation coefficient was found with satisfaction scale, swelling volume showed a weak correlation of Pearson's correlation test with FFI scores $(\mathrm{R}$ value $=0.190 ; \mathrm{p}$ value $=0.045)$. Conclusions This study revealed that the swelling of the foot and ankle following ankle fusion surgery are not associated with functional clinical outcome. However, because it affects the patients' satisfaction, we emphasize the need to identify the problem and management of the swelling, while assuring them that the swelling does not correlate with the early functional outcome.
\end{abstract}

Keywords: foot, ankle, swelling, FFI, satisfaction

\section{INTRODUCTION}

Patients commonly present with foot and ankle problems both in primary or secondary care clinics. Swelling is one of the prevalent reasons for patient's visit to the foot and ankle clinics along with pain, deformity, stiffness, instability, or abnormal gait. Generalized bilateral swelling that involves the whole foot and ankle is usually more related to systemic pathology such as cardiac or renal problems. Localized swelling is more likely results from some specific local pathologies, including inflammation, post-surgical or post-trauma consequences, vascular problems, or a specific problem such as Charcot neuroarthropathy [1]. As the foot swells, stiffness and pain appear. Previous studies showed that around $45 \%$ of patients may complain of ankle swelling five-year after ankle fracture fixation [2]. It has been reported that foot swelling disappeared at 18.6 weeks after tibial fracture in $50 \%$ of patients. It persisted in a small percentage of patients after 2 years or more [3]. However, clinical relevance between the amount of swelling and the functional clinical outcome is uncertain.
Ankle fusion has become the main surgical procedure for end-stage ankle arthritis. Ankle arthrodesis is used to relieve pain and improve the function of the foot in ankle degeneration. However it alters the biomechanical performance of the foot and ankle as the end goal is a well-aligned, stable ankle joint with the foot at a $90^{\circ}$-angle to the leg $[4,5]$. The ankle utilizes the calf muscle pump function to pump blood to the heart by muscle contraction [6,7]. Ankle stiffness after fusion prevents this pumping exercise, therefore swelling is commonly found.

Outcome parameters such as functional assessment, quality of life, or patient satisfaction have become fundamental tools for outcome evaluation after orthopaedic interventions. Objective treatment success is essential, but not the only condition which generates patient satisfaction [8]. To our knowledge, there are still limited studies evaluating swollen foot. The aim of this study was to measure the swelling volume of the foot and ankle after ankle fusion surgery, and to investigate its influence on functional clinical outcomes and patient satisfaction.

\section{MATERIAL AND METHODS}

A retrospective study was conducted involving patients with history of ankle fusion surgery due to primary end-stage ankle osteoarthritis, who presented to the foot-and-ankle clinic at Hasan Sadikin Hospital,
Bandung, Indonesia, from January 2017 to December 2019. The study period was chosen due to the beginning of documentation of quantitative swelling measurements at our clinic in 2017. 
Patients were examined for foot and ankle volume pre-operatively and at three months post-surgery. The time passage of three months was chosen because of the rehabilitation protocol used at our hospital that allows full weight-bearing daily activity in the third month post-operatively. Differences between two measurements were observed and documented as a quantification of the swelling volume ( $\Delta$ volume). Foot and ankle volume were measured with a water displacement technique as described by Brodovicz et al, using a foot volumeter, a clear rectangular box with a spout at the top of one of its short sides, as illustrated in Figure 1. The volumeter was filled with water until water rushed out of the spout. Once the water level was stable, the patient placed one foot in the volumeter and the displaced water was collected and measured in a graduated cylinder. The amount of water displaced equals to the volume of the foot and ankle [9]. Patients who presented a non-healing wound in the foot were excluded from the study due to unfavourable effect of foot immersion on the wound.

All the subjects had undergone a similar operative procedure. Patients only with a midline anterior approach were included into this study as it is the most common approach used in our hospital. This approach allows great exposure to the ankle joint. The ankle joint is exposed between the tibialis anterior tendon and the extensor hallucis longus tendon. The disadvantage of this incision is that it lacks exposure to the posterior ankle joint and the malleoli. Care must be taken to avoid damaging the medial dorsal cutaneous nerve [5]. We generally use three cancellous screws (DePuy Synthes, Germany) for fixation, except for some cases that needed a more stable construct (Fig. 2). Out of all the patients who had undergone ankle fusion, the ones who had fixation elements other than three cancellous screws for fixation, such as a plate, a nail, or more screws, were excluded from this study. It was crucial for the measurement, since the magnitude of postoperative volume was related to the amount or the size of the hardware.

Postoperative rehabilitation protocol was identical for all subjects as follows: (a) immediate postoperative ( elevation, compression, cold therapy); (b) non-weight bearing for 3 weeks (knee flexionextension, isometric exercise, and toe curls/spreads); (c) weeks 3-8 (partial weight bearing as tolerated, proprioception exercise, and muscle strengthening); and (d) full weight bearing as tolerated after 8 weeks.
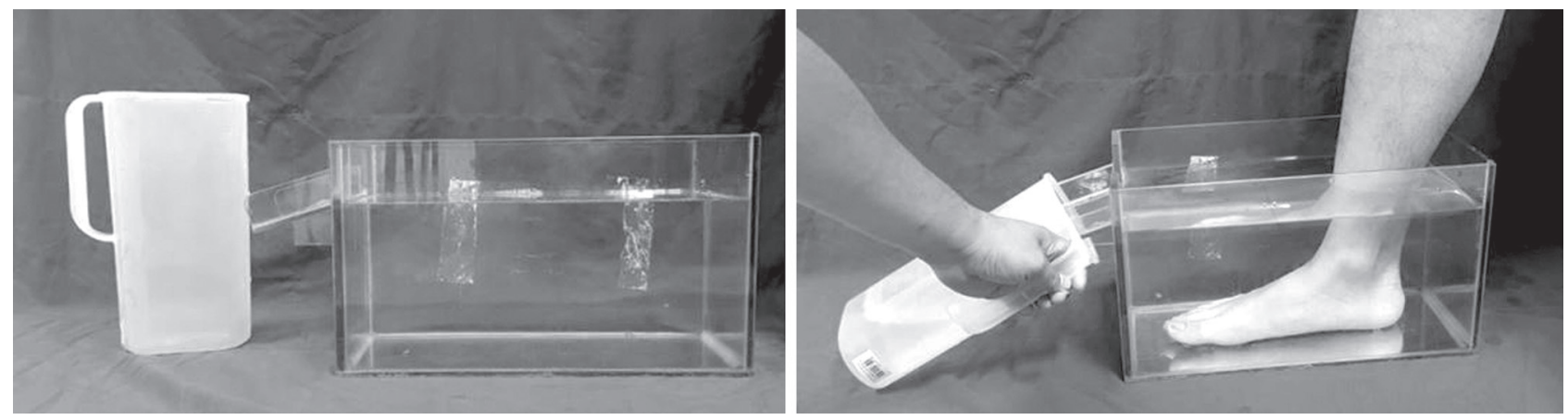

Fig. 1 Upper photo: water displacement volumeter set-up. Lower photo: illustration of volume measurement

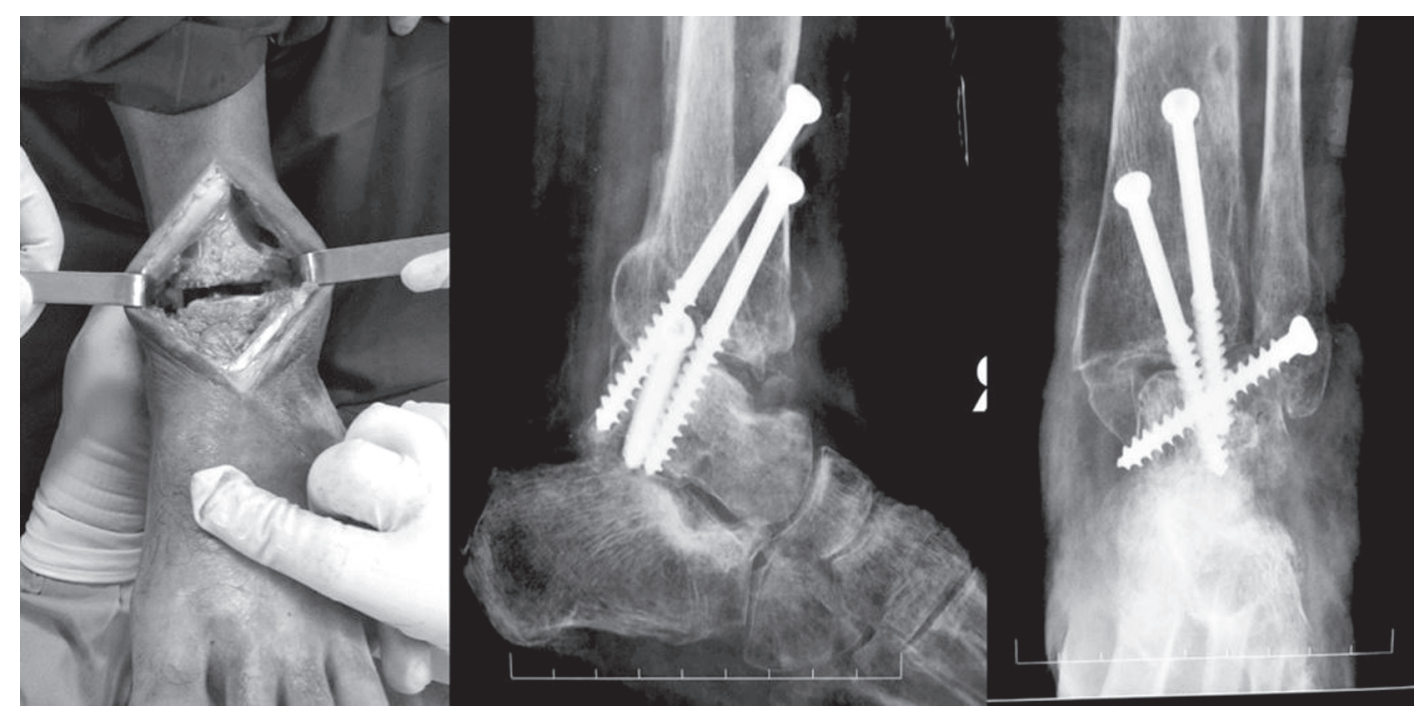

Fig. 2 Midline anterior approach of the ankle (left). Postoperative X-rays demonstrating the use of three cancellous screws for fixation (right) 
Foot function index (FFI) score and satisfaction scale were collected at a three months follow-up visit and analysed for the relationship with the swelling volume. FFI was shown as a reasonable tool for low functioning individuals with foot disorders. Agel et al concluded that this scoring system might not be appropriate for individuals who function at or above the level of independent activities of daily living [10]. For that reason, we use FFI for arthritis patient with some degree of disability. Pre-operative and three months post-operative FFI scores were collected.

Swelling volume were evaluated primarily as continuous variables. In order to investigate the correlations of FFI score and swelling volume, a bivariate analysis was performed using Pearson correlation coefficient. Additionally, we used a scatter plot to investigate the relationship as continuous variables. Statistical analysis was performed using IBM SPSS Statistics, Version 25.0 (IBM Co., NY, USA), and considered $\mathrm{p}$ values $<0.05$ to be statistically significant.

Ethical clearance from institutional review board of Hasan Sadikin Hospital was obtained before this study commenced.

\section{RESULTS}

Onehundredand twelve(112) patients were included in this study (Table 1). The majority were women $(58.3 \%)$ and the mean age was $59.75 \pm 6.81$ years. Most participants showed an increased post-operative foot and ankle volume after three months compared with pre-operative in a mean of $120.0 \pm 96.2 \mathrm{ml}$ (range, 5-400 ml). We found FFI scores' improvement in all patients, and the improvement ranged from $15 \%$ to $53 \%$, with a mean of $40.9 \pm 6.53 \%$. Satisfaction was assessed as satisfied (71 patients), indifferent (22 patients), dissatisfied (19 patients).

Table 1

Characteristics of the subjects

\begin{tabular}{|c|c|c|c|}
\hline \multicolumn{2}{|c|}{ Characteristics } & Results & Range \\
\hline \multicolumn{2}{|c|}{ Total number of patients } & 112 & \\
\hline \multicolumn{2}{|l|}{ Age (years) } & $59.75 \pm 6.81$ & $48 \sim 74$ \\
\hline \multirow{2}{*}{ Sex } & Female & 45 & \\
\hline & Male & 67 & \\
\hline \multicolumn{2}{|c|}{$\Delta$ Swelling volume $(\mathrm{ml})$} & $120.0 \pm 96.2$ & $5 \sim 400$ \\
\hline \multicolumn{2}{|c|}{ Preop FFI score (\%) } & $73.7 \pm 4.8$ & $68 \sim 81$ \\
\hline \multicolumn{2}{|c|}{ 3-mo post-op FFI score (\%) } & $32.88 \pm 5.0$ & $22 \sim 56$ \\
\hline \multirow{3}{*}{ Satisfaction } & Satisfied & 71 & \\
\hline & Indifferent & 22 & \\
\hline & Dissatisfied & 19 & \\
\hline
\end{tabular}

A correlation analysis was performed using the Pearson correlation coefficient to examine the relationships of swelling with a 3-months post-operative FFI score and satisfaction scale (Table 2). Although the correlation between swelling volume and the FFI score was significant, the Pearson correlation coefficient ( $\mathrm{R}$ value) was 0.190 , indicating weak correlation $(\mathrm{p}=0.045)$. In contrast, swelling volume showed a significant positive correlation, with a meaningful $\mathrm{R}$ value of $0.717(\mathrm{p}<0.001)$. A scatter plot was made to show the relationship between swelling volume and FFI scores as continuous variables. Likewise, they were not found to be related in the scatter plot (Fig. 3).

Table 2

Relationships of swelling volume with FFI score and satisfaction scale

\begin{tabular}{|l|c|c|}
\hline Variables & 3-mo FFI score & Satisfaction scale \\
\hline $\begin{array}{l}\text { R value by Pearson } \\
\text { correlation test }\end{array}$ & 0.190 & 0.717 \\
\hline $\begin{array}{l}\text { p value by Pearson } \\
\text { correlation test }\end{array}$ & 0.045 & $<0.001$ \\
\hline
\end{tabular}

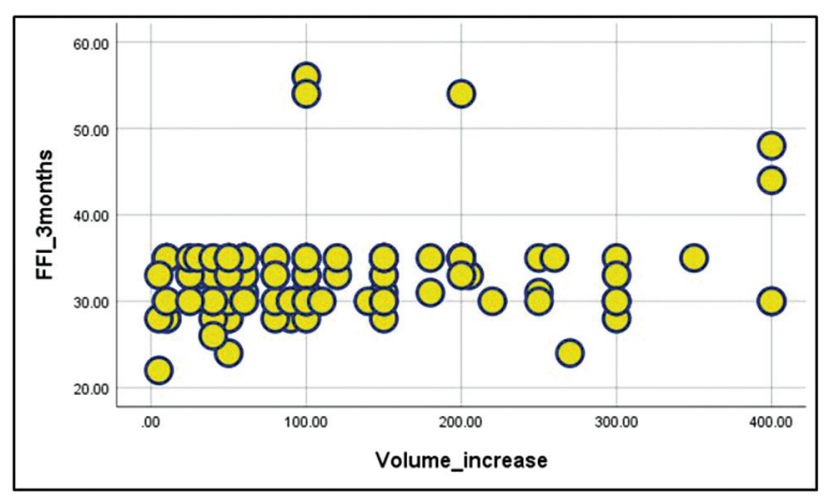

Fig. 3 Scatter plot of the relationship between swelling volume and FFI score at 3-months follow-up

\section{DISCUSSION}

Swelling or oedema is an accumulation of fluid in the interstitial space that occurs as the capillary filtration exceeds the limits of lymphatic drainage, producing noticeable clinical signs and symptoms [11]. Post-operative swelling occurs in a part as a result of the cytokine response to surgical injury, which increases the permeability of the capillary membrane to proteins such as albumin and results in redistribution of plasma proteins and fluid from the intravascular to the interstitial space. Swelling can alter surgical results functionally or cosmetically $[12$, 13]. The release of chemicals and compression of nerves in the area of injury causes pain.

The growth of population with ankle arthritis has led to the imperative need for effective ankle reconstruction surgeries. Other indications include chronic instability, Charcot neuropathy, failed total ankle arthroplasty, septic arthritis, avascular necrosis 
of the talus, and paralytic deformities when muscle tendon rebalancing is not possible [5]. Ankle fusion has been reported to be an effective surgery for pain relief and retaining plantigrade foot function. However, postoperative complications are common $[6,14]$. The use of tourniquets is common during foot and ankle surgery to reduce bleeding, improve visualization, and expedite the surgical procedures. However, there is a condition known as post-tourniquet syndrome, comprised of swelling, stiffness, and pale limb. The exsanguinated human limb will swell immediately by approximately $10 \%$ of its original volume after pneumatic tourniquet release. Reactive hyperemia and subsequent additional swelling can occur from hematoma formation and the accumulation of postanoxic oedema fluid $[15,16]$.

Numerous techniques for decreasing oedema have been introduced with varied results. Compression stockings application was one of the techniques that can reduce post-operative limb swelling and improve the rehabilitation process [17]. Other techniques are pneumatic impulse compression and cold compression therapy $[18,19]$. The use of cold compression therapy following either acute musculoskeletal injury or orthopaedic surgery had been reported as improving clinical outcomes compared to no treatment. The local application of cold suppresses the metabolic rate of the surrounding soft tissue, resulting in enzymatic activity reduction thus preventing tissue damage by hypoxia. Cold-induced vasocontriction also reduces extravasation of blood into surrounding tissues, local inflammation and oedema production. However because the benefits of cold compression therapy diminish with time, this intervention is thought to be most effective if applied almost immediately after injury or at the conclusion of an operative procedure [19, 20]. Grubhofer et al stated that compressive stocking had not shown any significant beneficial effects on subjective or objective outcome parameter of patients after hindfoot and ankle surgery, and coincided with low compliance due to the constricting effect of the stocking [21].

Bilateral leg swelling is a frequent symptom in older people and an important concern in geriatric medicine. The most probable cause of bilateral oedema in older patients is chronic venous insufficiency, heart failure, renal disease, liver disease, and drug-induced state [22]. In this study, we excluded bilateral swelling, therefore restricting the patients only to those having unilateral swelling associated with prior surgery. Similar result was also found regarding sex difference. There was no correlation between unilateral foot swelling and sex, otherwise there was bilateral swelling or related to gender-specific conditions such as pregnancy. Postoperative period was not significantly related to the amount of swelling. Various reports showed different duration of foot swelling [23]. Probable determinant were the preoperative swelling and the post-operative rehabilitation program, which were not evaluated in this study.

In contrary to the general concept, this study showed that FFI score was not significantly associated with swelling amount. This finding was likely attributable to varied post-operative period of the admitted patients. While acute or immediate post-operative oedema feasibly had an impact on pain and FFI score, the swelling at a longer follow-up period may not yield the same result. It has been postulated in literature that psychosocial factors, especially preoperative psychological distress, such as depression, is associated with poor clinical outcome. Yet the correlation was not confirmed in our evaluation [24]. Other studies stated an association between swelling and unsatisfactory outcomes after foot and ankle surgery [2, 21, 23, 25, 26]. However, most of them analysed the underlying diagnosis toward the functional outcome. None of them measured the relationship wielding the swelling as independent variable. One of the previous studies on clinical outcomes with oedema was conducted by Vaughan-Shaw et al that assessed qualitative oedema following emergency abdominal surgery [12]. Younger et al reported that swelling may be the cause of poorer outcomes in open ankle fusion compared to arthroscopic. Nevertheless, it was a different study approach compared with our study. In our study, all the patients received similar surgery and approach, with the result that some variables difference such as post-operative wound, soft tissue stripping, or extent of tourniquet use were eliminated. Furthermore, the same study also noted that between two procedures, total ankle arthroplasty and arthroscopic ankle arthrodesis, swelling scores for TAA were higher compared to AAA despite similar outcomes [27]. This indicates that swelling is not a sole determinant of clinical outcomes after ankle fusion surgery. Comparable to other prior studies of various surgical sites, swelling was a significant determinant of patients' satisfaction $[28,29]$. In our clinic, it is one of the most common complaints that brought the patients to the hospital, even if they fully returned to activity.

There were potential limitations in this study. First, the small sample size risks type II statistical error and may have resulted in some variations failing to reach statistical significance. Second, we aware of the ceiling effect of the satisfaction assessment. Ceiling effects can lead to serious artefact parameter estimates in most data analysis. Third, the underlying comorbidities were not explored sufficiently to be included in the assessment, and the exclusion of the feet with non-healing wound may affect the results. Further studies should include longer follow-up to identify mid-term and long-term effects of foot and ankle swelling on functional outcomes. 


\section{CONCLUSION}

This investigation established that the swelling of the foot and ankle after ankle arthrodesis is not a sole determinant of functional clinical outcome. However, it affected the patients' satisfaction with the outcome, regardless of the other clinical features. As fulfilment of expectations is an important determinant of patients' contentment, we emphasize the need to identify the problem and to manage swelling, while assuring them that the swollen foot does not always correlate with early functional outcome.

\section{REFERENCES}

1. Alazzawi S., Sukeik M., King D., Vemulapalli K. Foot and ankle history and clinical examination: A guide to everyday practice. World J. Orthop., 2017, vol. 8, no. 1, pp. 21-29. DOI: 10.5312/wjo.v8.i1.21

2. Shah N.H., Sundaram R.O., Velusamy A., Braithwaite I.J. Five-year functional outcome analysis of ankle fracture fixation. Injury, 2007, vol. 38, no. 11, pp. 1308-1312. DOI: 10.1016/j.injury.2007.06.002

3. Pun W.K., Chow S.P., Fang D., Cheng C.L., Leong J.C., Ng C. Post-traumatic oedema of the foot after tibial fracture. Injury, 1989, vol. 20, no. 4, pp. 232-235. DOI: 10.1016/0020-1383(89)90121-6

4. Wang Y., Li Z., Wong D.W., Zhang M. Effects of Ankle Arthrodesis on Biomechanical Performance of the Entire Foot. PLoS One, 2015, vol. 10, no. 7, pp. e0134340. DOI: 10.1371/journal.pone.0134340

5. DeHeer P.A., Catoire S.M., Taulman J., Borer B. Ankle arthrodesis: a literature review. Clin Podiatr. Med. Surg., 2012 , vol. 29 , no. 4, pp. 509-527. DOI: $10.1016 /$ j.cpm.2012.07.001

6. Toya K., Sasano K., Takasoh T., Nishimoto T., Fujimoto Y., Kusumoto Y., Yoshimatsu T., Kusaka S., Takahashi T. Ankle positions and exercise intervals effect on the blood flow velocity in the common femoral vein during ankle pumping exercises. J. Phys. Ther. Sci., 2016, vol. 28, no. 2, pp. 685-688. DOI: $10.1589 /$ jpts. 28.685

7. Ogiwara S. Calf muscle pumping and rest positions during and/or after whirlpool therapy. J. Phys. Ther. Sci., 2001, vol. 13, pp. 99-105.

8. Marks M., Herren D.B., Vliet Vlieland T.P., Simmen B.R., Angst F., Goldhahn J. Determinants of patient satisfaction after orthopedic interventions to the hand: a review of the literature. J. Hand Ther., 2011, vol. 24, no. 4, pp. 303-312. DOI: 10.1016/j.jht.2011.04.004

9. Brodovicz K.G., McNaughton K., Uemura N., Meininger G., Girman C.J., Yale S.H. Reliability and feasibility of methods to quantitatively assess peripheral edema. Clin. Med. Res., 2009, vol. 7, no. 1-2, pp. 21-31. DOI: 10.3121/cmr.2009.819

10. Agel J., Beskin J.L., Brage M., Guyton G.P., Kadel N.J., Saltzman C.L., Sands A.K., Sangeorzan B.J., SooHoo N.F., Stroud C.C., Thordarson D.B. Reliability of the Foot Function Index: A report of the AOFAS Outcomes Committee. Foot Ankle Int., 2005, vol. 26, no. 11 , pp. 962-967. DOI: $10.1177 / 107110070502601112$

11. Trayes K.P., Studdiford J.S., Pickle S., Tully A.S. Edema: diagnosis and management. Am. Fam. Physycian, 2013, vol. 88, no. 2, pp. 102-110.

12. Vaughan-Shaw P.G., Saunders J., Smith T., King A.T., Stroud M.A. Oedema is associated with clinical outcome following emergency abdominal surgery. Ann. R. Coll. Surg. Engl., 2013, vol. 95, no. 6, pp. 390-396. DOI: 10.1308/003588413X13629960046552

13. Wood W.A. Postoperative pedal edema. J. Foot Surg., 1977 Spring, vol. 16, no. 1, pp. 15-16.

14. Thomas R., Daniels T.R., Parker K. Gait analysis and functional outcomes following ankle arthrodesis for isolated ankle arthritis. J. Bone Joint Surg. Am., 2006, vol. 88, no. 3, pp. 526-535. DOI: 10.2106/JBJS.E.00521

15. Sharma J.P., Salhotra R. Tourniquets in orthopedic surgery. Indian J. Orthop., 2012, vol. 46, no. 4, pp. 377-383. DOI: 10.4103/0019-5413.98824.

16. Silver R., De la Garza J., Koreska J. Limb swelling after release of a tourniquet. Clin. Orthop. Relat. Res., 1986, no. 206, pp. 86-89.

17. Tischer T.S., Oye S., Lenz R., Kreuz P., Mittelmeier W., Bader R., Tischer T. Impact of compression stockings on leg swelling after arthroscopy - a prospective randomized pilot study. BMC Muskuloskelet. Disord., 2019, vol. 20, no. 1, pp. 161. DOI: 10.1186/s12891-019-2540-1

18. Gardner A.M., Fox R.H., Lawrence C., Bunker T.D., Ling R.S., MacEachern A.G. Reduction of post-traumatic swelling and compartment pressure by impulse compression of the foot. J. Bone Joint Surg.Br., 1990, vol. 72, no. 5, pp. 810-815. DOI: 10.1302/0301-620X.72B5.2211762

19. Block J.E. Cold and compression in the management of musculoskeletal injuries and orthopedic operative procedures: a narrative review. Open Access J. Sports Med., 2010, vol. 1, pp. 105-113. DOI: 10.2147/oajsm.s11102.

20. McMaster W.C., Liddle S. Cryotherapy influence on posttraumatic limb edema. Clin. Orthop. Relat. Res., 1980, no. 150, pp. $283-287$.

21. Grubhofer F., Catanzaro S., Schüpbach R., Imam M.A., Wirth S. Compressive Stockings After Hindfoot and Ankle Surgery. Foot Ankle Int., 2018, vol. 39, no. 2, pp. 210-218. DOI: $10.1177 / 1071100717737518$

22. Thaler H.W., Pienaar S., Wirnsberger G., Roller-Wirnsberger R.E. Bilateral leg edema in an older woman. Z. Gerontol. Geriatr., 2015, vol. 48, no. 1, pp. 49-51. DOI: 10.1007/s00391-013-0557-x

23. Finnan R., Funk L., Pinzur M.S., Rabin S., Lomasney L., Jukenelis D. Health related quality of life in patients with supination-external rotation stage IV ankle fractures. Foot Ankle Int., 2005, vol. 26, no. 12, pp. 1038-1041. DOI: 10.1177/107110070502601207

24. Oh J.H., Kim S.H., Ji H.M., Jo K.H., Bin S.W., Gong H.S. Prognostic factors affecting anatomic outcome of rotator cuff repair and correlation with functional outcome. Arthroscopy, 2009, vol. 25, no. 1, pp. 30-39. DOI: 10.1016/j.arthro.2008.08.010

25. Lash N., Horne G., Fielden J., Devane P. Ankle fractures: functional and lifestyle outcomes at 2 years. ANZ J. Surg., 2002, vol. 72, no. 10, pp. 724730. DOI: 10.1046/j.1445-2197.2002.02530.x

26. Ponzer S., Nåsell H., Bergman B., Törnkvist H. Functional outcome and quality of life in patients with Type B ankle fractures: a two-year follow-up study. J. Orthop. Trauma, 1999, vol. 13, no. 5, pp. 363-368. DOI: 10.1097/00005131-199906000-00007

27. Younger A.S., Daniels T.R., Wing K., Penner M.J., Glazebrook M.A., Veljkovic A., Wong H., Dryden P. Swelling results in poor outcome after ankle arthritis surgery. Proceedings of AOFAS Annual Meeting, 2016. Foot \& Ankle Orthop., 2016, vol. 1, issue 1.

28. Chen J.Y., Tao M.L., Tisnado D., Malin J., Ko C., Timmer M., Adams J.L., Ganz P.A., Kahn K.L. Impact of physician-patient discussions on patient satisfaction. Med Care, 2008, vol. 46, no. 11, pp. 1157-1162. DOI: 10.1097/MLR.0b013e31817924bc

29. Kocher M.S., Steadman J.R., Briggs K., Zurakowski D., Sterett W.I., Hawkins R.J. Determinants of patient satisfaction with outcome after anterior cruciate ligament reconstruction. J. Bone Joint Surg. Am., 2002, vol. 84, no. 9, pp. 1560-1572. DOI: 10.2106/00004623-200209000-00008

Received: 16.07 .2020

\section{Information about the authors:}

1. Raden Andri Primadhi,

Universitas Padjadjaran Medical School / Hasan Sadikin Hospital, Bandung, Indonesia, ORCID-ID 0000-0002-5825-5941,

Email: randri@unpad.ac.id

2. Renaldi Prasetia,

Universitas Padjadjaran Medical School / Hasan Sadikin Hospital, Bandung, Indonesia, ORCID-ID 0000-0001-5583-0835,

Email: renaldi.prasetia@gmail.com

3. Gibran Alpharian,

Universitas Padjadjaran Medical School / Hasan Sadikin Hospital, Bandung, Indonesia, ORCID-ID 0000-0003-3133-628X,

Email: gibrantristan@gmail.com

5. Hermawan Nagar Rasyid,

Universitas Padjadjaran Medical School / Hasan Sadikin Hospital, Bandung, Indonesia, ORCID-ID 0000-0003-4956-6788,

Email: hermawanphd@gmail.com 